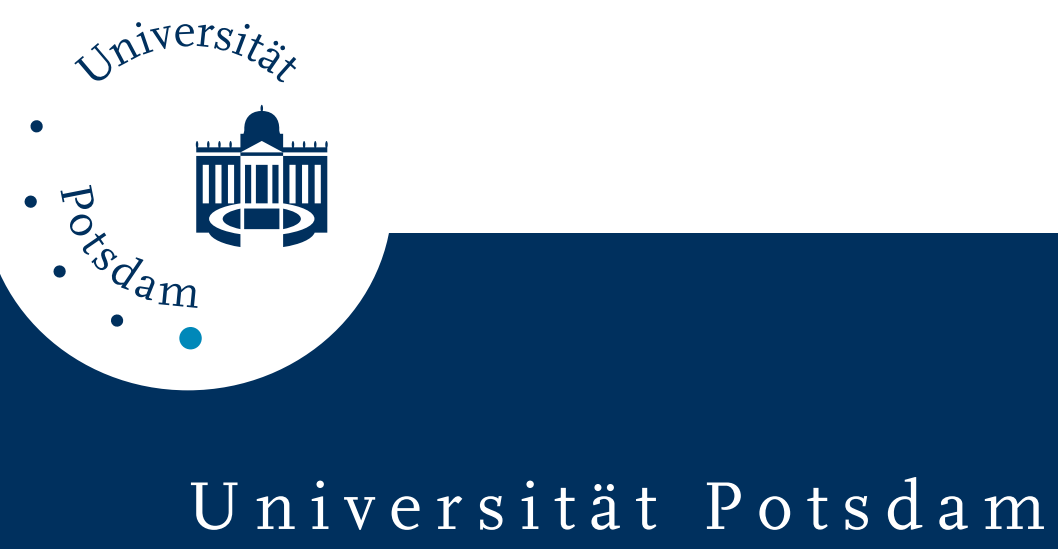

Embs, Frank ; Funhoff, Dirk ; Laschewsky, André ; Licht, Ulrike ; Ohst, Holger ; Prass, Werner ; Ringsdorf, Helmut ; Wegner, Gerhard ; Wehrmann, Rolf

\title{
Preformed polymers for Langmuir-Blodgett films- molecular concepts
}

first published in:

Advanced Materials, 3 (1991) S. 25-31, ISSN 0935-9648;

DOI 10.1002/adma.19910030106

Postprint published at the Institutional Repository of Potsdam University:

In: Postprints der Universität Potsdam

Mathematisch-Naturwissenschaftliche Reihe ; 81

http://opus.kobv.de/ubp/volltexte/2008/1719/

http://nbn-resolving.de/urn:nbn:de:kobv:517-opus-17196

Postprints der Universität Potsdam

Mathematisch-Naturwissenschaftliche Reihe ; 81 


\section{Preformed Polymers for Langmuir-Blodgett Films- Molecular Concepts **}

Amphiphilic Polymers Rod-like Polymers

LCPs Stability of LB Films

\section{By Frank Embs, Dirk Funhoff, André Laschewsky, Ulrike Licht, Holger Ohst, Werner Prass,* Helmut Ringsdorf, Gerhard Wegner, and Rolf Wehrmann}

The use of preformed polymers for the preparation of Langmuir-Blodgett (LB) multilayers is reviewed. Principles for polymer self-organization are outlined and the appropriate molecular designs are discussed. Recent developments in the different classes of polymers for LB multilayers are presented, and their outstanding properties highlighted.

\section{Stability of Langmuir-Blodgett Films}

Up to now the lack of stability of Langmuir-Blodgett (LB) films has been a serious problem which limited their use in scientific investigations and prevented industrial application. Conventional LB films are unstable in many respects: They dissolve easily in many solvents and often have a poor long-term stability. Furthermore their mechanical and thermal stability is quite low; LB-films often decompose at temperatures below $100^{\circ} \mathrm{C}$.

The major concept exploited to stabilize LB multilayers is to link the film-forming molecules together laterally. Consequently, simple polymers, such as polymethylmethacrylate and polyvinylacetate, ${ }^{[1]}$ were used initially for spreading at the air-water interface. Block copolymers have also been

\footnotetext{
[*] Dr. W. Prass

Zertrale Polymetforschung, Hoechst AO

D-6230 Frankfurt am Mitin 80 (FRG)

Dr. F. Embs, Prof. G. Wegner

Max Planck Institute for Polymer Research

Ackermannweg 10, D-6590 Matac (FRG)

Dr. D. Funhoff, Dr. U. Licht

BASF AG

Kunststoflaboratorium, D-6700 Ludwigshafen (FRG)

Dr. A. Laschewsky, Prof, H. Ringsdorf

Institute for Organic Chemistry, University of Mainz

Becher Weg 18-20, D-6500 Mainz (FRG)

Dr. H, Ohst, Dr. R. Wehrmann

Zentrale Forschung, Bayer AG

D-4150 Krefeld-Uerdingen (FRG)

[**] This work was supported by a roaterials research program by the Bundesministerium für Forschung und Technologie (BMFT) under Grant No. $03 \mathrm{M} 4008$
}

investigated. ${ }^{[2,3]}$ Although these polymers form monolayers which can be transferred onto solid substrates by the LB method, homogeneous and defect-free multilayers have not been obtained.

Further development was based on amphiphiles which conld be polymerized after film formation, preserving the structure of the initial LB filmo..$^{[4]}$ Generatly, the polymerization is induced by irradiation. ${ }^{[5-7]}$ Other means of polymerization such as polycondensation of films have also been investigated $^{[4.8-11]}$ and indeed, the polymerization improves stability towards mechanical, thermal and environmental attack.

Usually, the polymerization reactions induce structural reorganizations which can induce defects in the multilayers, e.g. by shrinkage. These problems can be minimized by appropriate molecular design. ${ }^{[14]}$ However, the control of the degree of polymerization, and the removal of unreacted monomers and side-products is not possible using this approach.

\section{LB Films by Spreading and Transfer of Polymers}

To overcome these problems, polymers are required which spread at the air-water interface forming a monolayer that can be transferred subsequently onto solid substrates resulting in a layered structure. Such polymers can be prepared monomer-free in macroscopic quantities ${ }^{[12-15]}$ with defined molecular weight and can be characterized by standard techniques

Two different principles are known at present, relating the tendency of the polymers to self-organize in LB films to molecular design criteria. The self-organization can be induced by attaching amphiphilic side chains to a polymer backbone of conventional flexible character or by creating a polymer backbone with a rod-like character decorated by flexible hydrophobic side chains. The latter is an entirely new principle in the design of molecules for LB films. 


\subsection{Amphiphilic Polymers}

In amphiphilic polymers or copolymers a main chain having a hydrophilic character due to either hydrophilic segments or side groups is rendered amphiphilic by long-chain, n-alkyl side groups ${ }^{[12-15]}$ (Fig. 1). Such polymers can be

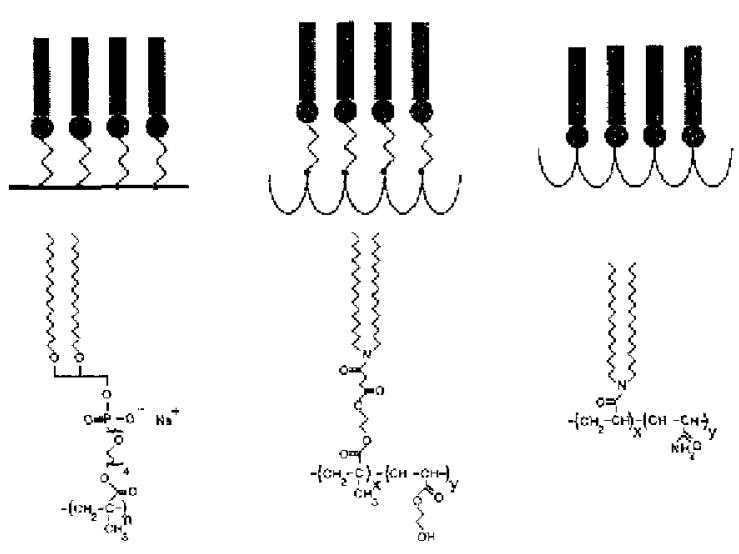

Fig. 1. Scheme of polymers self-organizing via side chains. Lefl) Side chain spacer. Center) Combired (side chain and main thain) spacer. Right) Main chain spacer.

prepared, for example, by homopolymerization of amphiphilic monomers bearing llexible side-chain spacer units (left). Alternatively, polymers with main-chain spacers can be prepared either by copolymerization of hydrophobic monomers with hydrophilic monomers (right), or by polycondensation or polyaddition reactions, ${ }^{[17,18]}$ Combination of the two kinds of spacer units resuits in a third type of amphiphilic polymers (center). ${ }^{[15]}$

\section{1.i. Vinyl Polymers}

A wide variety of amphiphilic polymers have been synthesized, e.g. tetraethyleneglycol-methacry]ates. ${ }^{[14]}$ alternating olefin-maleic anhydride and vinylether-maleic anhydride copolymers, ${ }^{191}$ random copolymers of octadecylacrylate or -methacrylate with hydrophilic monomers. ${ }^{[15,20,21]}$ These polymers show improved performance in terms of homogeneity and slability of the inultilayers. Additjonally, fluidity and mobility of the polymeric LB films can be optimized by using alkyl side-chains of different length in the same molecule, as depicted in Figure 2. It is a remarkable feature of polymers, that even monolayers in the fluid phase with conformationally disordered alkyl chains can be deposited to give homogeneous, stable LB films.

The vinyl copolymers are especially suited for the introduction of functional groups to tailor desired properties. As an example, comonomers car be incorporated which contain chromophores to be used in nonlinear optics (Fig. 3) or for further chemical modifications. [21]

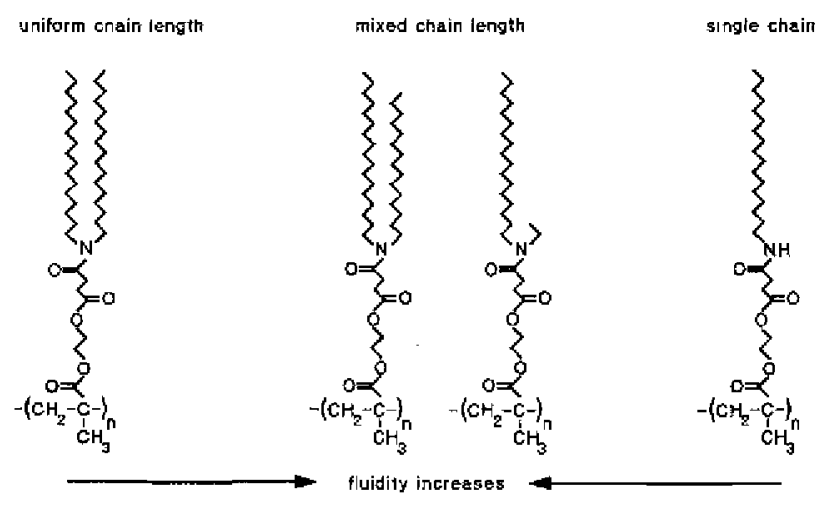

Fig. 2. Homopolymers with side chain spacers and mixed alkyl side chains to increase monofilm fluidity.

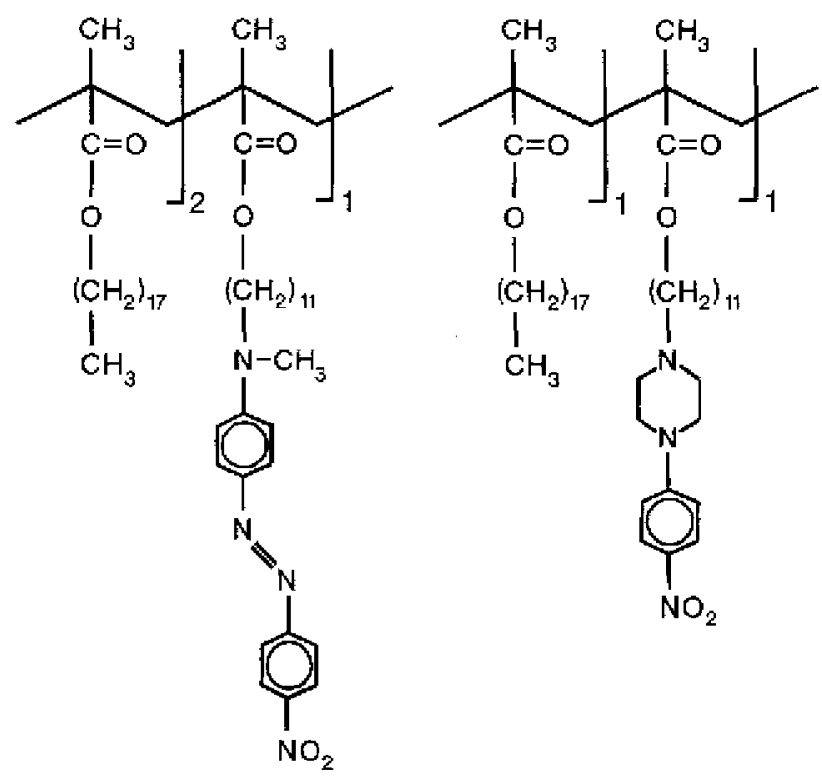

Fig. 3. Amphiphilic functional copolymers bentring nonlinear-oplic-active dyes.

\subsubsection{Polycondensation Polymers}

The use of polycondensation and polyaddition in polymer synthesis allows the incorporation of heteroatoms and of tailor-made main-chain spaccrs. Examples of amphiphilic polycondensation polymers are given in Figure 4. Mutitlayers constructed from polyamides and polyurethanes show a high thermal stability. Decomposition temperatures up to $200^{\circ} \mathrm{C}$ are observed, probably due to hydrogen bonding interactions of amide and urethane groups along the backbone. ${ }^{[221}$

\subsubsection{Amphiphilic Polymers by Polymer Analogous} Reactions

A number of different routes have been explored to implant amphiphilic character into common polymers via poly- 
<smiles>CCOc1cc(NNC)cc(N(O)C(O)CC(=O)Cl)c1</smiles><smiles>CCC(C=O)(CC)C(=O)OCO</smiles>

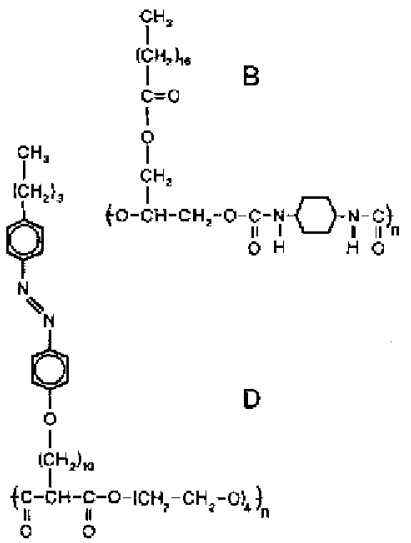

Fig. 4, Repeat units of amphiphilic a) polyamide [17] b) polynrethane c) polyester [18] and d) liquid srystaline polyester [48]

mer analogous reactions. Examples are the functionalization of styrene-maleic anhydride copolymers, ${ }^{[2]}$ the treatment of poly(epichlorohydrine) to introduce a chromophore as well as an alkyi side chain by a two-step synthesis, ${ }^{[23]}$ acidcatalyzed acetalization of long-chain aldehydes with poly(vinylalcohol) ${ }^{[24]}$ or reaction of poly(allylamine) with perfluorinated alkylisocyanates or -esters ${ }^{[25]}$ to produce urethanes or amides.

Special interest was concentrated on hydrophobic poly(siloxanes) due to the simplicity of their modification and their etch resistance in microlithography, which is shown for LB multilayers of an amphiphilic polysiloxane in Figure 5.

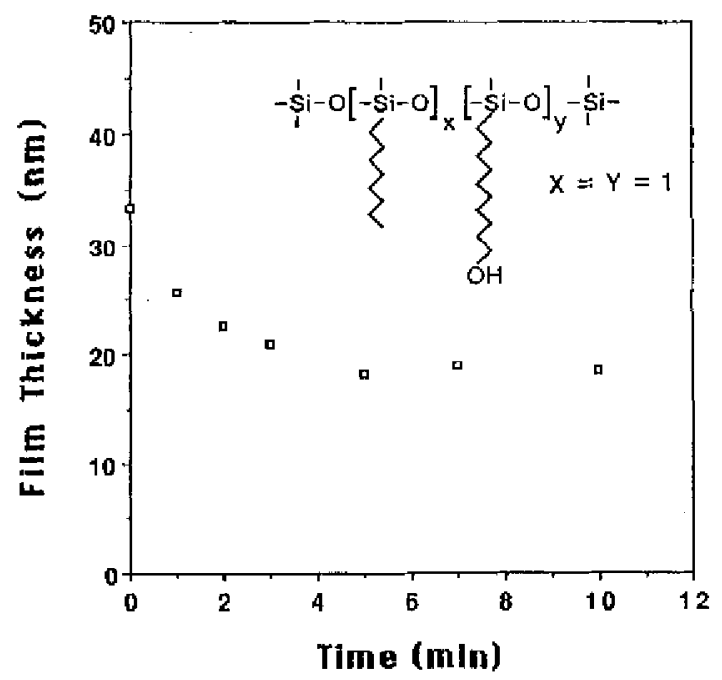

Fig. 5. Resistance towards oxygen plasma of a 30 layer LB film built up from an amphiphilic polysiloxane. Plasma : $\mathrm{PO}_{2}=0.2 \mathrm{mbar}$, power $=20 \mathrm{~W}$.

The spreading behavior of poly(dialkylsiloxanes) on the water surface has been investigated already ${ }^{[27]}$ including the study of polymers in the floating process. ${ }^{(28]}$ Detailed surface-pressure-area diagrams have been reported for sev- eral types of conventional polysiloxanes ${ }^{129-321}$ and copolymers. Modification of the structure of the polysiloxanes in order to optimize the formation of $L_{,} B$ films has been neglected in the past.

Attempts to transfer halogenated polysiloxanes as stacked monomolecular films on a substrate have been recently published, ${ }^{[33]}$ as well as the preparation of amphiphilic siloxanes via hydrosilylation of poly(methylsiloxanes). These polymers were functionalized with chromophores for measurements of nonlinear optical properties. ${ }^{[34-35]}$ This approach towards amphiphilic functional poly(siloxanes) has been extended by the design of copolymers with different types of side chains to obtain a variety of multilayer properties. In particular, appropriate hydrophilic head groups have been combined with side groups to produce poly(siloxanes) with solid-analogue behavior at the air-water interface (compare Figure 6 ). These polymers are superior in multilayer produc-
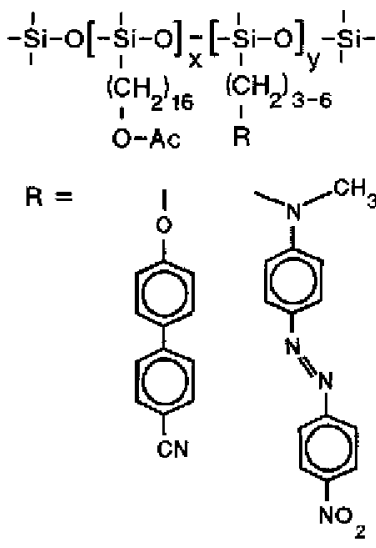

$$
X=Y=1
$$

Fig. 6. New amphiphilic copoly(siloxanes) with different functionalities.

tion compared to the often fluid-like standard products. New functions, like chromophores useful for nonlinear optics and units which provide sites for light-jnduced curing reactions can be introduced in this way.

\subsubsection{Lipid Polyelectrolyte Complexes}

If the amphiphiles at the air-water interface expose an ionic hydrophilic group to the aqueous subphase they must be counterbalanced by oppositely charged counterions. An interesting case arises if Iow molecular weight amphiphiles of this type interact with high molecular weight poly-ions dissolved in the subphase. Anionic dialkylphosphates and cationic vinylpyridinium polymers for example have been used to study such interactions by which the polymeric species in the subphase become strongly adsorbed to the monolayer. The resulting polyelectrolyte-lipid complexes are easily transferred to build up LB multilayers. ${ }^{[36-43,21]}$ Uniform multilayers are obtained in this way with modified physical 


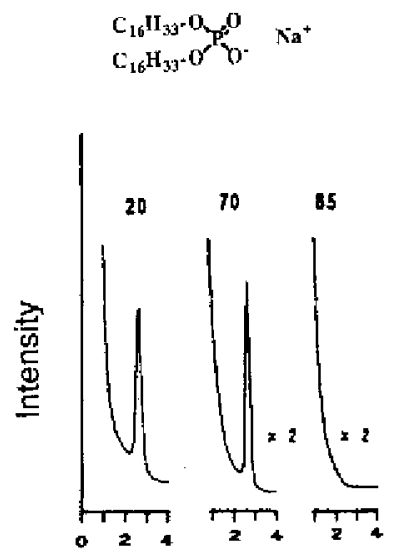

$\mathrm{C}_{16} \mathrm{H}_{33}-\mathrm{Q}$
$\mathrm{C}_{16} \mathrm{H}_{33}-\mathrm{O}^{2}$
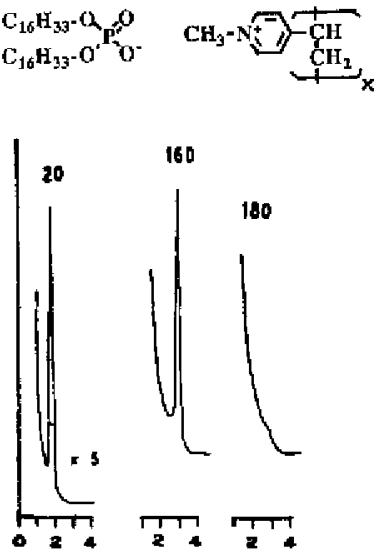

Scattering Angle $2 \theta$

\section{Scattering Angle $2 \theta$}

Fig. 7. Temperature-dependent $\mathrm{X}$-ray scattering of mustilayers of dicetylphosphate. Comparison of the sudjum sali and of the noly(methylpyridinium) poivelectrolyte complex. Bilayer spacing $D_{1}=3.4 \mathrm{~nm}, D_{2}=5.3 \mathrm{~mm}$. The numbers above the peaks indicate the temprature.

properties compared to the multilayers built from the uncomplexed amphiphiles, e.g. different optical spectra or modified bilayer spacing (Fig. 7).

Such complexed LB multilayers show improved properties, as illustrated here by their enhanced thermal stability. The melting temperature of selected complexed multilayers can be improved by as much as $100^{\circ} \mathrm{C}^{[40]} \mathrm{As}$ an illustrative example, the relationship between structure and order as measured by temperature-dependent X-ray diffraction is shown in Figure 7. The complexation of the lipids in the multilayers by polyelectrolytes has a similar consequence with respect to thermal stability as polymerization of the constitutive units of the I.B layer. A large pool of readily accessible lipids with ionizable groups and polyelectrolytes can be combined in many ways to give rise to such complexes, saving much synthetic work. The separate synthesis of the

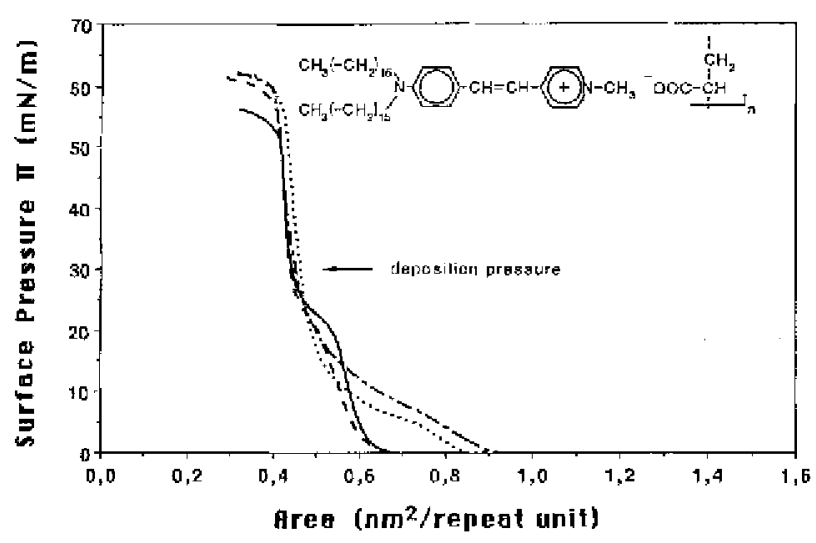

Fig. 8. Spreading behavior of an amphiphilic hemicyanine complex with different concentrations of poly (acrylie acid) in the subphase $(\mathrm{pH} 6.0)$ al $20^{\circ} \mathrm{C}$ (---): on pure water. (---): $0.1 \mathrm{mg}$ polyfacrylic-acidy/l. (....): $1 \mathrm{mg}$ poly (acrylic-acid);. (----): $100 \mathrm{mg}$ poly(acrylic-acid);.

polyelectrolyte and of the lipid bearing the functional groups may avoid complications in the synthetic or polymerization procedures involved when chemically sensitive groups such as chromophores have to be incorporated into the LB structurc. Hemicyanines ${ }^{155}$ show (Fig. 8) how a direct attachment of a sensitive dye to the polymer backbone is circumvented by complexation. Although the lipid depicted in Figure 8 does not give multilayers when used directly, complexation with poly(acrylic-acid) enables the preparation of transparent, deeply colored, uniform multilayers, which arc stable up to $120^{\circ} \mathrm{C}$. The stoichiometric composition of such deposited complexes has not yet been fully analyzed. ${ }^{[38]} \mathrm{A}$ recent, interesting feature of lipid-polyelectrolytc complexes is their use as precursors for ultrathin polymer films, including polyimides. ${ }^{[4-43]}$ In the first step, multilayers of the amine-poly(amide-acid) complex are transferred. In a second step, removal of the multilayer-forming lipid by thermal treatment and a simultaneous curing process produces an ultrathin polyimide coating on the support..$^{[4-43]}$

\subsection{Amphiphilic Liquid-Crystalline Polymers}

The search for improved thermal stability of LB multilayers led to the replacement of the hydrocarbon chains of the amphiphiles with fluorocarbon chains and/or aromatic moieties. In particular, mesogenic aromatic mojeties have been incorporated ${ }^{[4,45]}$ with the result of improved thermal stability. Whether further liquid crystatline (LC) phases with improved mobility of the mesogenic units can be achieved and used to heal delects like grain boundaries in these multilayers is a matter of speculation at present. However, the idea of constructing such "amphotropic LB multilayers" [2 I] which can undergo phase transitions to thermotropic liquidcrystalline phases without destruction of the multilayer architecture is intriguing. In addition to their improved thermal behavior, many mesogenic amhiphiles are investigated because they contain chromophores ${ }^{149,501}$ of interest for nonlinear optical studics.

Amphiphilic LC polymers ${ }^{[21,40,45-50]}$ have been used to combine the effect of the polymer backbone and of the mesogenic side chain. $A$ s found for classical polymeric amphiphiles, satisfying spreading and deposition bchavior of the LC polymers is observed when appropriate side-chain or main-chain spacer groups are present ${ }^{[40,48.51]}$ (Fig. 3d). The copolymers are particularly suited for the preparation of high-quality multilayers with good themal stability. Interestingly, these multilayers exhibit complex rcorganization processes and thermochromic behavior ${ }^{[40,51]}$ which are not yet understood. Hence, no general picture has yet emerged of how the mesogenic groups will influence the multilayer properties in detail. Most recently it was shown that the preparation of LA multilayers is not restricted to polymers forming calamitic LC phases. Some polymers which form discotic LCs are suitable, such as the ones shown in Figurc 9, offering new ways to stabilize multilayers. ${ }^{[52,53]}$ 


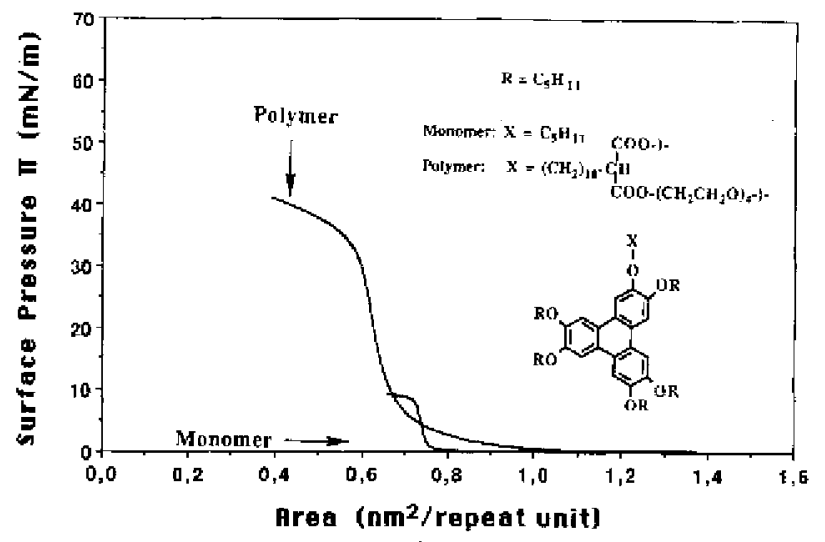

Fig. 9. Spreading behavior of monomeric and polymeric discotic LCs at $20^{\circ} \mathrm{C}$.

\subsection{Rod-like Polyners}

Rod-like polymers can be organized in the form of LB fitms for reasons related to the stiffness of their backbone. Stable monolayers are formed by polymers which exhibit groups with few or very small polar functions. Typical examples of such polymers are phthalocyaninato-polysiloxanes, ${ }^{[16]}$ several polyglutamates in the $\alpha$-helix conformation, ${ }^{[20,57-63,65,66]}$ special cellulose alkylethers, ${ }^{[54,56,641}$ specifically substituted polysilanes ${ }^{1681}$ etc. These polymers cannot be classified according to the rules developed to specify amphiphilic compounds.

Surface-pressure-area diagrams of rod-like polymers are known for cellulose esters, ethylcellulose ${ }^{[54,56]}$ and polypeptides in the $\alpha$-helix conformation, like poly(benzylaspartate) and poly(methylglutamate). ${ }^{[57-59]}$ The behavior of polypeptides as monolayers at the air-water interface has been studied extensively. However, the transfer of only one such layer to quartz substrates with persistence of the $\alpha$-heiix conformation in the transferred layer (measured using IR spectroscopy) has been reported. ${ }^{[6]}$ In the case of multilayers, an hexagonal packing of the $\alpha$-helix chains has been proposed based on SAXS results. ${ }^{[61\}}$ Preferential alignment of the polypeptide backhones parallet to the dipping direction was found by circular dichroism ${ }^{[62]}$ and polarized IR spectroscopy. ${ }^{163]}$

Generally, the deposition behavior of polypeptides ${ }^{[60-63]}$ and also of some cellulose derivatives ${ }^{[54]}$ was reported to be very poor and therefore these materials were not considered to be suited for formation of multilayers with a reasonable degree of perfection.

As a new concept to overcome this problem, rod-like polymers surrounded by conformationally mobile side chains to prevent crystallization and to provide mobility of the stiff backbones within the monolayer ${ }^{[16,20,65,661}$ have been developed. As a general route, rod-like polymers are decorated by alkyl chains of different length wrapping the individual backbones with a skin of liquid-like segments. Thus, the structure of these polymers is quite different to that of con- ventional amphiphilic molecules forming $L B$ films. It should be remembered that the stability of conventional L.B layers depends on the fact that a close packing of chains with longrange order within the layer can be achieved, which is not the case for the molecules discussed in this section.

This type of polymer is represented best by an unsymmetrically substituted phthalocyaninato-polysiloxane. ${ }^{[16]}$ More than 200 layers of these molecules can be transferred easily onto hydrophobic substrates. Stable L.B films of high quality are formed in which the backbones are oriented preferentially parallel to the dipping direction. The spreading, compressing, transfer and packing in layers of these molecules is schematically depicted in Figure 10.

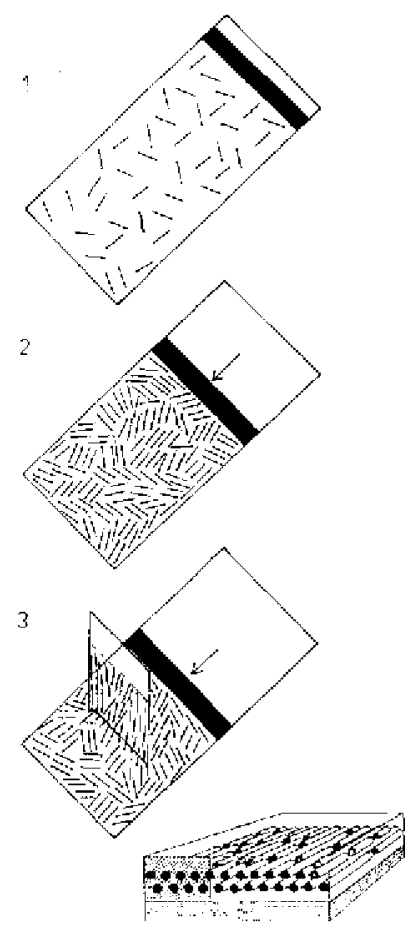

Fig. 10. Rod-like polymer-forming ordered LB multiluyers. 1) Spreading of dilute polymer solution and evaporation of the solvent. 2) Compression of the molecules to form a dense monolayer. 3) Transfer of the monolayer to a solid substrate with simultaneous alignment of the polymer backbones and alignment of the molecules on the substrate.

High-quality multilayers of $\alpha$-helix poly(alkylglutamates) ${ }^{[20,65-67]}$ can only be built up when the side chains are disordered. This is achieved by selecting copolymers with an appropriate ratio of long and short alkyl side chains. A detailed investigation was carried out for poly(methyl-cooctadecylglutamate) where a ratio of methyl/octadecyl of $3 / 10$ to $6 / 10$ was found to be the optimum.

Recent experiments with cellulose ethers are in agreement with these results. Good transfer properties are obtained when cellulose is etherified to contain partly methoxy and partly lauryloxy side chains. Alternatively, the cellulose 
ethers of a branched alcohol like isopentanol show excellent performance in the preparation of multilayers.

Substituted poly(diphenylsilanes) are rod-like polymers found to form LB films. ${ }^{[08]}$ The backbone of these polysilanes is stiffened by two phenyl residues per repeat unit and the attraction to the water surface is provided by alkoxygroups. The shape of the surface-pressure-area diagrams (Fig. 11) indicates that defined monolayers are not obtained

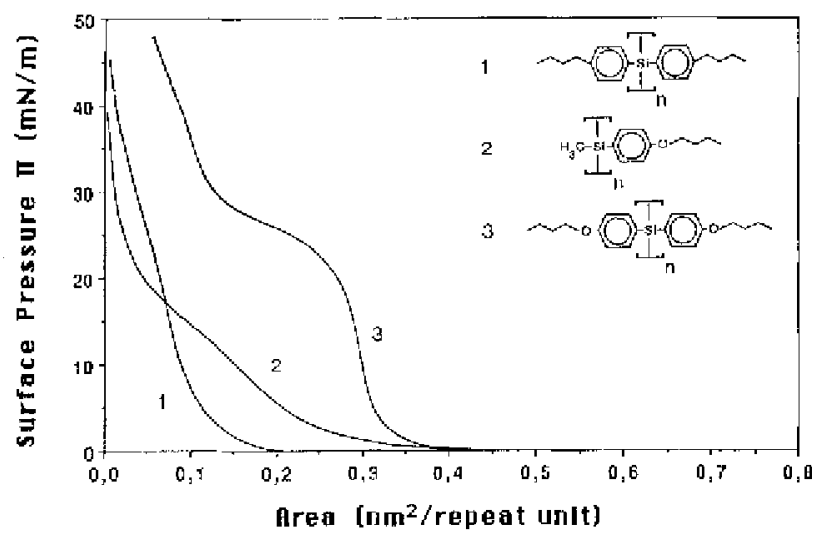

Fig. 11. Surface-pressure-area diagram of polysilanes with different substituents. 1) Poly[bis-(p-butylphenyl)silane]. 2) Poly[methyl-(p-butoxyphenyl)silane]. 3) Poly[bis-( $p$-butoxyphenyl)silanc]

fot completely hydrophobic polysilanes (1) or partly polar polysilanes with only one phenyl ring per repeat unit (2). However, poly(bis-butoxyphenylsilane) forms stable monolayers and can be transferred to hydrophobic substrates to provide weil-ordered multilayers. The multilayers formed by these rod-like poylmers generally show order with regard to alignment of the back bone to the dipping direction, (Fig. 10). This orientation of the polymer backbones can be improved by annealing at $120^{\circ} \mathrm{C}$ subsequent to the deposition.

\section{Summary and Perspectives}

Polymers are versatile materials for LB multilayers. The structural variety of useful polymers seems to be unlimited, stretching from classical vinyl polymers via polycondensates, polyelectrolyte complexes, and LC polymers, to rod-like macromolecules. Polymets offer incteased thermal stability, and simple functionalization of the resulting multilayers compared to low molecular weight compounds. In particular, phase scparation, which often appears in monolayers prepared from mixed compounds, can be overcome when the layers are linked together covalently. Also, different functionalities can be combined at will. In contrast to low molecular weight analogues, polymeric monolayers are useful even in the fluid state, Furthermore, novel principles, such as rods in fluid matrices, can be realized using polymers. In this way, unusual multilayer properties, like in-plane anisotropy, are accessible. Because of these outstanding properties, polymers are facing a bright future in LB-work.

Received: June 1, 1990

[1] G. L. Gaines Jr.: Insoluble Monolayers at Liquid-Gas Interfaces, Interscience, New York 1966, pp. 264. 274.

[2] Y. Ikuda, H. Lwata, S. Nagaoka, F. Horii, M. Hatada, J. Macromol. Sci Fhys. B $17(1980)$ ist.

[3] M.Niwa, N, Katsurada, N. Higashi, Macromolecules 21 (1988) 1878.

[4] A. Baniel, M. Fránikel, I. Friedrich, A. Katehalsky, J. Org. Chent. 13(1948) 791

[5] R. Ackermann, O. Enacker, H. Ringsdorf, Kolloid-Z. u. Z. Polym. 24 , (1971) 1118 .

[6] D. Nacgele, H. Ringndorf, B. Tieke, G. Wegner, D. Day, J. B. Lancio, Chemiker Zeilung 10 (1976) 426.

[7] H. Badet, K. Dorn, B. Hupfer, H. Ringsdorf, Adv. Palym. Sci. 64 (1985)

[8] A. Barraud, C. Rosilio, A. Ruaude]-Teixier, Thith Solid Films 68 (1980) 7.

(9) R. Neamann, H. Ringsiorf, J. Am. Chem. Soc. 108 (1986) 487.

[10] A. Batraud, A. Ruaudel-Teixier, C. Rosilio, Ann. Chim. t0 (1975) 195.

[11] W. N. Emmerling, B. Pfannemüller, Colloid Polym, Sci. 26t (1983) 677.

[12] R. H. Tredgold, C. S. Winter, J. Phys. D 15 (1982) LS5

[13] P. Hodge, E. Khoshdel, R. H. Tredgold, A. J. Vickers, C. S. Winter, Br Polym. J. 17 (1985) 368

[14] R. Elbert, A. Laschewsky, H. Ringsdorf, J. Am. Chemt. Soc. 107 (1985) 4134.

[15] A. Laschewsky, H. Ringsdorl, G. Schmidt, J. Schneider, J. Am. Chem. Soc. $109(1987) 788$

[16] E. Orthmann, G. Wegner, Angew. Chem. Int. Ed. Engl. 25 (1986) 1105 Angew. Chem, 98 (1986) 1114

[17] D. Lupo, W. Prass, LJ. Scheunemann, Thin Solid Films 178 (1989) 403

[18] D. Nerger, H. Ohst, H.-C. Schopper, R. Wehrmann, Thin Solid Films 178 (1989) 253

[19] P. Hodge, E. Khoshdel, R. H. Tredgold, A. J. Vickers, C. S. Winter, Brit Polym. J. $17(1985) 368$

[20] G. Duda, A. J. Shoulen, T. A. Anndt, G. Lieser. G. F. Schmidt C. Bubeck, G. Wegner, Thin Solid Films 159 (1988) 221.

[21] H. Ringsdorf, B. Schlarb, J, Veazmer, Angew. Chem. 27 (1988) 113; Angew. Chem. 100 (1988) 117

[22] P. Tippmann-Krayer, H. Riegler, M. Paudler, H. Möbwald, H.-U. Sienmund, J. Eickmans, U. Scheuremam, U. Licht, W. Schtepp, Adr. Katcr. 3 (1991) 46.

[23] R. C. Hall, G. A. Lindsay, B. Anderson, S. T. Kowel, B. G. Higgins, P. Strove, Mater. Res. Sot. Symp. Proc. 100 (1988) 35.1

[24] K. Oguchi, T. Yoden, K. Sanui, N. Ogata, Polym. J. 58 (1986) 887.

[25] A. Sekiya, M. Tamura, H. Ishida, M. Watanabe, Chem. Leth. (1988) 1223

[26] R. Jones, C. S. Winter, R. H. Tredgold, P. Hodge, A. Honrtar, Poijmer 28 (1987) 1619

[27] H. W. Fox, P. W. Taylor, W. A. Zisman, Ind, Eng. Chem. 39 (1947) 1401

[28] W. Noll, H. Steinbach, C. Sucker, Kolloid-Z. u. Z. Polym, 204 (1965) 94.

[29] W. Noll, H. Steinbach, C. Sucker, J. Polym. Sci. C 34 (1971) 123.

[30] S. Granck, S. J. Clirson, T. R. Formoy, J. A. Serlyen, Polymar 26 (1985) 925.

[31] S. Granick, J. Herz, Macromolecules 18 (1985) 460.

[32] G. Gabrielli, P. Baglioni, I. Colloid. Interface $5 \%, 73$ (1980) 582.

[33] K. Kawaguchi, Y. Takeya, Jpr. Pat. Appt. J6 1164-676-A, Teijin KK (1986).

[34] W. Carr, M. J. Goodwin, A. M. McRoberts, G. W. Gray, R. Marsden, R. M. Scrowstone, Makromol. Chem. Rapid Commun. 8 (1987) 487.

[35] G. W. Gray, W. D. Hawthorne, J. S. Hill, D. Lacey, M. S: Lee, G. Nestor, M. S. White, Prlymer 30 (1989) 964.

[30] W. MeNaughtan, K. A. Snook, F. Caspi, Biochim. Biophys. Acta 818 (1985) 132 .

[37] M. Shimomura, T. Kunitake, Thin Solid Films 132 (1985) 243.

[38] N. Higashi, T. Kunitake, Chem. Lett. 1986, 105.

[39] A. Takahara, N. Morotoni, S. Hiraoka, N. Higasti, T. Kunitake, T. Kajiyama, Marromolecules 22 (1989) 617

[40] C. Erdelen, A. Laschewsky, H. Ringsdorf, J. Schneider, A. Schuster, Thin Solid Fibms 180 (1989) 153.

[41] M. Suzuki, M. Kakimoto, T. Konishi, Y. Imai. M. Iwanoto, T. Hino, Chem. Let $1986,105$.

[42] M. T. Fowier, M. Suzuki, A. K. Engel, K. Astno, T. Itoh, J. Appl. Phys. 62 (1987) 3427 . 
[43] U. Ticht, W. Schrepp. unpublished results.

[44] 0. Albrcht. W. Cumming, W, Kreuder, A. Laschewsky, H. Ringsdorf, Colloid Poiym. Sci. 264 (1986) 659.

[45] R. 1f. Tredgold, R. A. Allen. P. Hodge, Thin Solid Filow 155 (1987) 143

[46, K. A. Suresi, A. Biumstein, F. Rondelez, J. Phys. (Paris) 46 (1985) 453.

[47] A. J. Vickers, R. H. Tredgold, P. Hodge, E. Khoshdel, I. Girliug, Thin Sold Films 134 (1985) 43.

48 A. Schuster, Diplona Thesis, Mainz 1986

[49] 11. Ringsdorf, A. Schuster, J. Schneider, Abstr, 3rd tht. Conf, LangmuirBlodgent Fims, Göttingen 1987.

[50) M. Carpeuter, P. N. Prasad, A. C. Griffin, Thin Solid Füm 161 (1988) 31

[51] T. Pcrner, H. Ringsdorf, I, S. Schildkraut, A. Schuster, Macromolecules, in press.

52) O. Karthats, H Rinesdorf, C. Urban, Angew, Materomol. Chem., in press.

[53] A. Laschewesky, Adv. Mater. 1989, 392; Angew. Chem. Int Ed. Engl Adv Mater. 28 (1989) 1574; Angew. Chem. Adv. Mater, tof (1989) 1606.

[54] J. R. Katz, P. J. Samwell, Nature 16 (1928) 592.

[55] D. Lupo, W. Pruss, U. Scheunemanth. A. Laschewsky, H. Rinssdorf, I Ledoux, S. Opi. Soc. Am. BS (1988) 300 .
[56] M. Hitmeier, L. S, Sandell, P luner, J Polm. Sci. C36 (1971) 267.

[57] B. R. Matcom, Nature 195 (1962) 901

[58] B. R. Malcom, Proc. R. Soe, London, Ser, A 30.5 (1968) 363

[59] D. W. Gaupil, F. C. Goodrich, J. Colloid inlerfare Sci. 62 (1976) 142

[60] G. I. Loeb, R. E. Baier. J. Collotd Interface Sci. 27 (1968) 38.

[61] J. P. Green, M. C. Phillips, G. G. Shipley, Biochim. Biophys. Ac'a 330 (1973) 243

[62] D. G. Cotncl1, J. Colloid Inerface Sci. 70 (1979) 167

[63] F. Takeda, M. Matsumoto, T. Takenaka, Z. Fujiyoshi, N. U Jyeda, .f Colioid Interface $S c$. 91 (1983) 267.

[64] T. Kawaguchi, H. Nakahara, K. Fukuda, Thin Solid Films I33 (1985) 29.

[65] G. Duda, A. J. Schouten, T. Andt, G. Lieser, G. F. Schmidt, C. Buheck, G. Weener, Thin Solid Finwe 159 (1988) 221

[66] G. Duda. G. Wegner, Makromol. Chem. Rapid Commun. 9 (1988) 496.

[67] W. Hickel, G. Duda, G. Wegner, W. Knoll. Makromol. Chem. Rapid Com mun 10 (1989) 353 .

[6R] F. W. Embs, G. Wegner, D. Neher, P. Albuuy, R. D. Miller, C. G. Willson, W. Schrepp. Macromolecules, in press. 